\title{
Sulfurized activated carbons and their mercury adsorption/ desorption behavior in aqueous phase
}

\author{
N. $\operatorname{Asasian}^{1} \cdot$ T. Kaghazchi'
}

Received: 6 September 2014/Revised: 27 February 2015/Accepted: 19 April 2015/Published online: 30 April 2015

(C) Islamic Azad University (IAU) 2015

\begin{abstract}
Sulfurized activated carbons (SACs) are of the most recent forms of modified sorbents with high affinity toward mercury. The adsorption/desorption behavior of SACs has not been studied in detail in liquid phases. The study was carried out with the aim of recognition of similarities and differences in the properties and performances of SACs and activated carbons (ACs) exposing to aqueous-phase mercury. In this study, three different sulfurizing agents including dimethyl disulfide (DMDS), elemental sulfur (S), and sulfur dioxide $\left(\mathrm{SO}_{2}\right)$ were tested for AC sulfurization (each under the optimal conditions). Sulfurization with DMDS at room temperature led to the formation of elemental sulfur and sulfide/disulfide on the AC surface; however, sulfurization at higher temperatures with $\mathrm{SO}_{2}$ and powdered $\mathrm{S}$ resulted in the formation of more stable organic forms such as thiophene and oxidized sulfur. The equilibrium mercury adsorption capacity of $\mathrm{AC}-$ DMDS was so larger than AC and other SACs. On the other hand, the largest surface area drop and consequently the slowest mercury adsorption rate belonged to this sample. However, $\mathrm{AC}-\mathrm{S}$ and $\mathrm{AC}-\mathrm{SO}_{2}$ led to moderate increase in mercury equilibrium adsorption capacity; they showed several advantages resulted from their extended porosities and more stable sulfur functionalities. The more accelerated adsorption especially at initial stages of contact in
\end{abstract}

N. Asasian

n.asasian@gmail.com

1 Department of Chemistry, Faculty of Science, Islamic Azad University, Rasht Branch, Pol-e-taleshan, P.O. Box 41335-3516, Rasht, Iran

2 Chemical Engineering Department, Amirkabir University of Technology, No. 424, Hafez Ave., P.O. Box 15875-4413, Tehran, Iran batch modes and negligible entry of sulfur compounds into the treating wastewater were of their important advantages. Mercury desorption was also studied and compared using several acidic and potassium halide solvents. The possibility of applicability of SACs in consecutive mercury adsorption/desorption cycles was also investigated.

Keywords Adsorption - Desorption - Mercury · Sulfurized activated carbon - Wastewater treatment

\section{Introduction}

Mercury is a bioaccumulative and persistent pollutant. However, most of the mercury entering the environment is emitted to the air; it can easily transfer from air to soil and water (Huber 1997; US EPA 1997). The presence of mercury in aquatic systems above the allowable limits leads to irreparable risks to the living organisms (Eisler 2006). One of the simple and economically attractive ways to reduce mercury in wastewaters and aqueous systems is adsorption by activated carbons or other adsorbents $(\mathrm{Kr}-$ ishnan and Anirudhan 2002b; Kadirvelu et al. 2004; Al Rmalli et al. 2008; Asasian and Kaghazchi 2013a). Though the removal efficiency of AC is primarily linked to its welldeveloped internal pore structure and total surface area, the chemistry of the surface (the nature and amount of functional groups) is of paramount importance in the removal of ionic or polar species such as mercury ions (Edwin 2008). Many recent researches have focused on the modification of surface properties of ACs in order to improve their selectivity and capacity when used in industrial applications (Yin et al. 2007). The studies showed that ACs after introduction of sulfur-containing groups exhibit enhanced mercury removal efficiency over the parent carbon, 
due to the formation of mercuric sulfide on the carbon surface (Korpiel and Vidic1997; Nam et al. 2003). In detail, the high affinity of SACs toward mercury could be explained using the Pearson's hard-soft acid-base (HSAB) theory (Pearson 1998). Based on the theory, mercury cations as soft acids prefer binding to the sulfur groups (soft bases). However, there is no such a strong attraction between mercury and oxygen-containing groups. Oxygen groups are the dominant functionalities on the surfaces of conventional ACs and classified as hard bases. On the other hand, sulfur functional groups have negligible affinity toward hard acids such as $\mathrm{Ca}^{2+}, \mathrm{Mg}^{2+}$, and $\mathrm{Fe}^{2+}$ which usually exist in wastewaters as interfering ions. This is exactly the reason of the improved selectivity of the sulfurized adsorbents toward mercury (Asasian et al. 2014).

Practically, sulfur is introduced into the structure of ACs according to several procedures including treatment with sulfur dioxide, hydrogen sulfide (Macias-Garcia et al. 2003), elemental sulfur (Korpiel and Vidic1997; Nabais et al. 2006; Asasian and Kaghazchi 2013a), carbon disulfide, and other sulfur-containing solutions such as $\mathrm{Na}_{2} \mathrm{~S}$ and $\mathrm{K}_{2} \mathrm{~S}$ (Ranganathan and Balasubramanian 2002; Wajima et al. 2009; Silva et al. 2010). For example, Otani et al. 1988 in order to obtain a mercury-selective sorbent treated a kind of $\mathrm{AC}$ by soaking in a $\mathrm{CS}_{2}$ solution of sulfur, followed by evaporating the solvent in $\mathrm{N}_{2}$ gas. The maximum sulfur content was about $13.1 \mathrm{wt} \%$, and a decrease in the surface area was also observed from 1250 to $710 \mathrm{~m}^{2} / \mathrm{g}$ (Otani et al. 1988). Liu et al. 1998 experienced different methods for sulfurization of a commercially bituminous coal-based AC (BPL). They found that the best method for the introduction of sulfur into the BPL structure was mixing fine powder sulfur with carbon in a single boat (with the optimized sulfur-to-carbon ratio $(\mathrm{SCR}=4 / 1)$ ) and heating the mixture at $600{ }^{\circ} \mathrm{C}$. They increased the sulfur content and mercury adsorption capacity of SACs by sealing of the tube furnace and stopping the $\mathrm{N}_{2}$ inert flow during the heating procedure (Liu et al. 1998, 2000). S-C, S-H, S-O, and short linear-chain sulfur allotropes were detected on the surface of SACs produced. The higher importance of sulfurization temperature rather than SCR was of the other results of their work (Liu et al. 1998, 2000), which was confirmed by Skodras et al. 2002. Skodras also studied the porosity loss during the sulfurization and found it more severe in the case of microporous ACs (Skodras et al. 2002). Many other researchers have extensively investigated the influence of different properties of SACs (such as the weight percent of sulfur in the bulk and surface structure, the type of sulfur groups, surface area, mean pore width, and...) on the $\mathrm{Hg}$ adsorption capacity from gaseous phase (Korpiel and Vidic 1997; Liu et al. 1998; Vitolo and Pini 1999; Liu et al. 2000; Hsi et al. 2001; Vitolo and Seggiani 2002; Feng et al.2006a). In contrast, there are limited classified data on the application of SACs for $\mathrm{Hg}$ adsorption from aqueous systems. For example, Anoop Krishnan and Anirudhan produced sulfurized adsorbents with the sulfur content of $8.9 \mathrm{wt} \%$ in the forms of $\mathrm{C}=\mathrm{S}, \mathrm{S}=\mathrm{O}$, and $\mathrm{S}-\mathrm{S}$ by treatment of carbonized bagasse with $\mathrm{SO}_{2}$ and $\mathrm{H}_{2} \mathrm{~S}$, respectively, at $400{ }^{\circ} \mathrm{C}$. The simultaneous activation and sulfurization of bagasse resulted in a small porosity loss. The sulfurized bagasse was applied for mercury uptake from chlor-alkali wastewaters (Krishnan and Anirudhan 2002b). Mohan soaked a fertilizer-based low-cost $\mathrm{AC}$ in $\mathrm{CS}_{2}$ for $24 \mathrm{~h}$ and observed an increase in the maximum uptake of $\mathrm{Hg}$ (II) from $1.78 \times 10^{-3}$ to $3.98 \times 10^{-3} \mathrm{~mol} / \mathrm{g}$ from wastewater (Mohan et al. 2001). Ranganathan and Balasubramanian sulfurized a coconut shell-based AC by mixing and shaking of AC with a sodium sulfide solution $(0.5 \%)$ for $1 \mathrm{~h}$. The mercury equilibrium adsorption capacity of the virgin one was $40 \mathrm{mg} / \mathrm{g}$ which increased to $60 \mathrm{mg} / \mathrm{g}$ (Ranganathan and Balasubramanian 2002). In the previous works of our group, sulfurization of AC through different methods has been reported (Asasian and Kaghazchi 2012, 2013b; Asasian et al. 2014).

The present work extending the previous studies of this group tries to give more detailed classified information about the common characteristics of different kinds of SACs and their behavior toward aqueous-phase mercury. The kinetic, equilibrium, activation, and thermodynamic constants of mercury adsorption were calculated and explained. Besides, the efficiency of various solvents for mercury desorption from the surface of saturated SACs was studied and compared. The current research was carried out in the Separation Laboratory of Chemical Engineering Department of Amirkabir University of Technology (Tehran Polytechnic) in 2011.

\section{Materials and methods}

\section{Sulfurization and characterization}

A commercial kind of bituminous coal-based AC (Jacobi Carbons Company) was sulfurized according to three different procedures as follows: the first method was the simple impregnation of $10 \mathrm{~g} \mathrm{AC}$ in $50 \mathrm{~cm}^{3}$ of dimethyl disulfide (DMDS) solution and mixing the suspension with the speed of $200 \mathrm{rpm}$ for $48 \mathrm{~h}$ at room temperature $\left(30^{\circ} \mathrm{C}\right)$ (Asasian and Kaghazchi 2012). The second method was a two-step sulfurization procedure including (1) AC impregnation in the molten elemental sulfur at $145{ }^{\circ} \mathrm{C}$ for 30 min with the sulfur-to-carbon ratio (SCR) of $4: 1$, and (2) stabilization of the physically sorbed sulfur by heat treating of the solid mixture at $600{ }^{\circ} \mathrm{C}$ for $30 \mathrm{~min}$ in a muffle furnace under an inert atmosphere (Asasian and Kaghazchi 2013b). In the third method, AC was contacted 
with a stream of sulfur dioxide $\left(\mathrm{SO}_{2}\right)$ diluted in $\mathrm{N}_{2}$ (concentration of $4 \% \mathrm{vol} / \mathrm{vol}$ ) in a bubbling fluidized bed reactor at $700{ }^{\circ} \mathrm{C}$ for $60 \mathrm{~min}$ (Asasian et al. 2014). The detailed procedures and the ways of achieving the abovesaid optimal conditions were described in the previous works (Asasian and Kaghazchi 2012, 2013b; Asasian et al. 2014). The SACs were denoted as AC-DMDS, AC-S, and $\mathrm{AC}-\mathrm{SO}_{2}$, respectively.

The sulfurized and sulfur-free ACs were characterized by the use of surface area and porosimetry analysis, CHNS/ O elemental analysis, XPS and FTIR spectroscopy (Shimadzu spectrometer), SEM-EDAX analysis, and point of zero charge $\left(\mathrm{pH}_{\mathrm{pzc}}\right)$ measurement (Smiciklas et al. 2000). The porous properties of the adsorbents were measured by physical adsorption-desorption of nitrogen at $77 \mathrm{~K}$, in an automatic volumetric apparatus (Quantachrome NOVA 1000). Degassing of the SACs was performed at $110^{\circ} \mathrm{C}$ for $4 \mathrm{~h}$ to prevent the volatilization of unstable sulfurs before the measurements. The Brunauer-Emmet-Teller and Horvath-Kawazoe equations were applied for calculation of specific surface area and micropore volume (Lowell et al. 2004). The weight percentages of sulfur in the bulk structure of the samples were determined using a CHNS/O elemental analyzer (Thermo Model Flash EA1112). The detection of different elements exactly on the surface of the samples was performed using SEM-EDAX analysis (TESCAN, Model VEGAII fitted with an energy-dispersive spectrometer microanalysis (SAMx)). XPS data were collected by a VG Microtech instrument consisting of a XR3E2 X-ray source, a twin anode $\left(\mathrm{Mg} K_{\alpha}\right.$ and $\left.\mathrm{Al} K_{\alpha}\right)$, and a concentric hemispherical analyzer (CHA). Before the analysis, the powdered samples were inserted into the ultrahigh vacuum chamber $\left(10^{-7} \mathrm{mbar}\right)$. The spectrometer was calibrated with the binding energy of the $\mathrm{C} 1 \mathrm{~s}$ line $(284.6 \mathrm{eV})$. The procedure for measuring $\mathrm{pH}_{\mathrm{pzc}}$ of the samples was as follows: $50 \mathrm{~cm}^{3} \mathrm{KNO}_{3}$ solution $(0.1 \mathrm{M})$ was poured into several Erlenmeyer flasks. The $\mathrm{pH}$ of solutions within each flask was adjusted to a value between 1 and 12 , by adding $\mathrm{HNO}_{3}$ or $\mathrm{KOH} 0.1 \mathrm{M}$. Then, $0.10 \mathrm{~g}$ adsorbent was added to each flask, and the final $\mathrm{pH}$ was measured after shaking the mixtures for $48 \mathrm{~h}$ at room temperature. The $\mathrm{pH}_{\mathrm{pzc}}$ was defined as the point where $\mathrm{pH}_{\text {final }}$ equaled $\mathrm{pH}_{\text {initial }}$ (Smiciklas et al. 2000). The detection of the unreacted elemental sulfur groups in the structure of SACs was carried out by the procedure suggested by Danwanichakul (Danwanichakul et al. 2008). The method was based on the solubility of unreacted elemental sulfur in toluene.

\section{Mercury adsorption/desorption experiments}

The required mercury solutions for the experiments were prepared by the use of $\mathrm{HgCl}_{2}$ (Merck). The measurement of mercury concentration was taken using an atomic absorption spectrophotometer (Varian AA240). The rate of mercury adsorption by the sorbents was studied with a series of kinetic experiments under the following conditions: initial concentration of $200 \mathrm{mg} / \mathrm{L}$; adsorbent dosage of $1.0 \mathrm{~g} / \mathrm{L}$; initial $\mathrm{pH}$ of 7.0; agitation speed of $200 \mathrm{rpm}$; and temperature of 30,45 , and $60{ }^{\circ} \mathrm{C}$. The sampling was carried out after shaking the samples for varying intervals between $5 \mathrm{~min}$ and $48 \mathrm{~h}$. The operating conditions of the equilibrium tests were similar to those of the kinetic experiments with the difference that enough time (48 h) was given to the samples to reach equilibrium. The initial concentration of mercury solutions was selected in the range of $50-800 \mathrm{mg} / \mathrm{L}$ in the equilibrium tests. The influence of the initial $\mathrm{pH}$ on the mercury adsorption capacities of the sorbents was studied by varying the value between 2.0 and 10.0 at room temperature $\left(30^{\circ} \mathrm{C}\right)$.

The desorption experiments were carried out on the saturated sorbents which have already adsorbed mercury under the following conditions: initial concentration of $300 \mathrm{mg} / \mathrm{L}$, adsorbent dosage of $1.5 \mathrm{~g} / \mathrm{L}$, initial $\mathrm{pH}$ of 7.0 , agitation speed of $200 \mathrm{rpm}$, and contact time of $48 \mathrm{~h}$. The performance of different solvents including two strong acids $-\mathrm{HCl}$ and $\mathrm{HNO}_{3}$ - and three types of potassium halides- $\mathrm{KCl}, \mathrm{KBr}$, and $\mathrm{KI}-(2 \mathrm{M})$ in desorption of mercury was investigated. These experiments were carried out by shaking the samples with the dosage of $2 \mathrm{~g} / \mathrm{L}$ for $24 \mathrm{~h}$ at $30{ }^{\circ} \mathrm{C}$.

All of the tests were performed at least twice under identical conditions. It was confirmed that the experimental results were reproducible within at most $5 \%$ error.

\section{Results and discussion}

\section{Properties of sulfurized activated carbons}

Table 1 shows the porosity and chemical properties of the sulfurized activated carbons in comparison with AC. Under the optimal conditions used, all the three sulfurizing agents succeeded to increase the bulk and surface sulfur content of $\mathrm{AC}$ to the values about 10 and $6 \mathrm{wt} \%$, respectively. The results are in accordance with the data previously published. For example, Macias-Garcia obtained a SAC with the sulfur content of $9.9 \mathrm{wt} \%$ by heat treating of a commercial $\mathrm{AC}$ at $900{ }^{\circ} \mathrm{C}$ in the presence of $\mathrm{H}_{2} \mathrm{~S}$. It was observed that the two-stage treatment of $\mathrm{AC}$ (first at $30^{\circ} \mathrm{C}$ successively in $\mathrm{SO}_{2}$ and $\mathrm{H}_{2} \mathrm{~S}$, and then in the presence of $\mathrm{N}_{2}$ for $30 \mathrm{~min}$ at $200{ }^{\circ} \mathrm{C}$ ) led to the increase in sulfur content to $10.2 \mathrm{wt} \%$ (Macias-Garcia et al. 1993). By sulfur impregnation of BPL at $600{ }^{\circ} \mathrm{C}$ with the $\mathrm{SCR}=4 / 1$, Liu et al. 1998 produced SACs with the sulfur content in the range of 10.04-10.18 wt\%. In another work, the sulfur 
Table 1 Porosity and chemical properties of the sulfurized and sulfur-free ACs

\begin{tabular}{|c|c|c|c|c|c|c|c|c|c|c|}
\hline Adsorbent & $\begin{array}{l}\text { Bulk sulfur } \\
(\mathrm{wt} \%)\end{array}$ & $\begin{array}{l}\text { Surface sulfur } \\
(\mathrm{wt} \%)\end{array}$ & $\begin{array}{l}S_{\mathrm{BET}} \\
\left(\mathrm{m}^{2} / \mathrm{g}\right)\end{array}$ & $\begin{array}{l}\text { Loss of } \\
S_{\text {BET }}(\%)\end{array}$ & $\begin{array}{l}V_{\mathrm{MIC}} \\
\left(\mathrm{cm}^{3} / \mathrm{g}\right)\end{array}$ & $\begin{array}{l}\text { Loss of } \\
V_{\text {MIC }}(\mathrm{c} \%)\end{array}$ & $\begin{array}{l}V_{\mathrm{TOT}} \\
\left(\mathrm{cm}^{3} / \mathrm{g}\right)\end{array}$ & $\begin{array}{l}\mathrm{MIC} . \\
\%\end{array}$ & $\begin{array}{l}\text { Average pore } \\
\text { width }(\AA)^{\mathrm{a}}\end{array}$ & $\mathrm{pH}_{\mathrm{pzc}}$ \\
\hline $\mathrm{AC}$ & 1.5 & - & 828 & - & 0.39 & - & 0.55 & 71.0 & 26.5 & 10.4 \\
\hline AC-DMDS & 9.6 & 6.2 & 348 & 57.97 & 0.15 & 61.54 & 0.30 & 50.0 & 34.4 & 7.7 \\
\hline $\mathrm{AC}-\mathrm{S}$ & 10.8 & 5.3 & 596 & 28.02 & 0.29 & 25.64 & 0.40 & 72.5 & 27.2 & 7.1 \\
\hline $\mathrm{AC}-\mathrm{SO}_{2}$ & 11.0 & 6.9 & 751 & 8.57 & 0.36 & 7.69 & 0.52 & 69.2 & 27.7 & 7.3 \\
\hline
\end{tabular}

${ }^{\text {a }}$ Average pore width calculated from $\left(d_{\text {mean }}=4 V_{\mathrm{TOT}} / S_{\mathrm{BET}}\right)$

content of sulfurized powdered ACs after treating with $\mathrm{CS}_{2}$ and $\mathrm{Na}_{2} \mathrm{~S}$ for $48 \mathrm{~h}$ reached 13.5 and $7.3 \mathrm{wt} \%$, respectively (Zhang et al. 2003).

After sulfurization with DMDS, elemental sulfur, and $\mathrm{SO}_{2}$, the primary surface area decreased by 58,28 , and $8.6 \%$, respectively (Table 1 ). The observed loss in the surface area, micropore, and total pore volume of AC after sulfurization caused by the sulfur-containing particles plugged the pores. Shifting of the average pore width toward larger values after sulfurization indicates the blocking of micropores. Skodras et al. 2007 acclaimed that the effect of sulfur addition on the BET surface area of mesoporous ACs is negligible compared to microporous ones. Sinha and Walker, the first researchers worked on AC sulfurization, oxidized $\mathrm{H}_{2} \mathrm{~S}$ by $\mathrm{O}_{2}$ at $140{ }^{\circ} \mathrm{C}$ to introduce sulfur into the structure of a carbonized Saran (Sinha and Walker 1972). They observed that for sulfur loading of $11.8 \mathrm{wt} \%$, surface area decreased from 875 to lower than $1 \mathrm{~m}^{2} / \mathrm{g}$. In the work, the largest drop belonged to AC-DMDS which was produced using a liquid sulfurizing agent at room temperature. In contrast, in the case of $\mathrm{AC}-\mathrm{SO}_{2}$, applying a gaseous sulfurizing agent and high-temperature treating led to the lowest porosity blockage in spite of introduction of the same amount of sulfur (Asasian and Kaghazchi 2012, 2013b; Asasian et al. 2014). The weakness of SACs in physisorption of pollutants and their slower initial adsorption rate compared to the parent AC could be attributed to the limited porosity of the sorbents. It will be pointed in more detail in the following subsection (Mercury adsorption by sulfurized activated carbons).

Table 1 also shows that sulfur addition into the AC structure-via all three procedures-led to the acidification of its surface and declining $\mathrm{pH}_{\mathrm{pzc}}$ from the severe basic $\mathrm{pH}$ (10.4) to almost neutral ( 7) (Asasian and Kaghazchi 2012, 2013b; Asasian et al. 2014). This property of SACs facilitates the electrostatic interaction with mercury cations, and so it promotes the adsorption capabilities of the adsorbents (Krishnan and Anirudhan 2002a, b).

\section{Mercury adsorption by sulfurized activated carbons}

The kinetic constants of mercury adsorption were calculated using the pseudo-second-order kinetic rate expression of Ho and McKay (1999). Considering the adsorption mechanism of divalent metals by activated carbons, it is established that the variation in metal adsorption rate before reaching equilibrium can be described well using this model (Krishnan and Anirudhan 2002b). The values of kinetic constants and the correlation coefficients at three different temperatures are shown in Table 2. The good agreement of the experimental data and the model can be deduced from $R^{2}$ and RMSE values. The pseudo-second-order rate $\left(k_{2}\right)$ and the initial sorption rate $\left(h_{\mathrm{i}}=k_{2} q_{e}^{2}\right)$ constants for the SACs were found smaller than those of AC. As it was noted previously, the slower initial sorption rate of the sulfurized sorbents is a consequence of their limited porosity, and especially in the batch mode experiments, it is considered as a weak point. It is observed that AC-DMDS with the highest loss in the surface area and porosity adsorbed mercury slower than the others. However, the equilibrium adsorption capacity $\left(q_{\mathrm{e}}\right)$ of this sample was so larger than $\mathrm{AC}$ and the other sulfurized ones. Based on the $\mathrm{Hg}$ adsorption capacity graphs versus time (not shown here) (Asasian and Kaghazchi 2012, 2013b; Asasian et al. 2014), at the initial stages of contact, the adsorption capacities $\left(q_{\mathrm{t}}\right)$ of SACs were smaller than AC. Under such conditions, given the dominance of the physisorption mechanisms, it was not unexpected that the faster adsorption occurred by the adsorbent with the more developed porosity and larger surface area (non-sulfurized AC). After some time ( $\sim 150 \mathrm{~min}$ for AC-DMDS and $\sim 60 \mathrm{~min}$ for the other SACs), the adsorption capacities of sulfurized sorbents shifted to the larger values than AC. It was attributed to the beginning of the contribution of sulfur functionalities in mercury uptake through chemisorption, complex formation, or other interactions (Asasian and Kaghazchi 2012, 2013a; Asasian et al. 2014; Macias-Garcia et al. 2004). Table 2 shows that adsorption at higher temperatures could improve the adsorption rate to some extent. It is notable that by applying sulfurized ACs for mercury adsorption in the fixed-bed systems, their slow initial adsorption rate would not be very problematic. Because in continuous systems, the time necessary to reach the static equilibrium is not a determining factor, and the sorbents with the highest equilibrium adsorption capacities could lead to the longer breakthrough times and wider curves. 
The equilibrium results at three different temperatures were fitted with two of the most common isotherm models (Langmuir and Freundlich) in adsorption from diluted aqueous solutions (Freundlich 1906; Langmuir 1918). The values of isotherm parameters as well as the correlation coefficients are summarized in Table 3, which indicate the goodness of the fit with both models. Table 3 shows that the amounts of the equilibrium monolayer adsorption capacity $\left(q_{\mathrm{m}}\right)$ do not obey a regular trend. For example, in the case of AC-DMDS, the values of $q_{\mathrm{m}}$ were smaller than the corresponding values of $\mathrm{AC}$, and in several cases, an indistinctive trend was observed with increasing temperature. It may indicate that the monolayer adsorption mechanism which is primarily dependent on the formation of a single layer of adsorbate on the internal surface area of the adsorbents cannot fully determine the adsorptive behavior of sulfurized sorbents toward mercury ions. In contrast, the multilayer adsorption capacity $\left(K_{\mathrm{F}}\right)$ of the sorbents showed a rational trend. The other parameter of Freundlich isotherm $(1 / n)$ had smaller values in the case of SACs attributed to their stronger interactions with mercury (Tseng and Wu 2008).

Considering the relative equality of the sulfur contents of all SACs, it is necessary to explain the reason of the higher mercury adsorption capacity of AC-DMDS rather than $\mathrm{AC}-\mathrm{S}$ and $\mathrm{AC}-\mathrm{SO}_{2}$ in spite of its limited porosity. Figure 1 shows the normalized $\mathrm{Hg}$ adsorption capacities of SACs $\left(\mathrm{mg} / \mathrm{m}^{2}\right)$ versus their normalized sulfur contents (mg/ $\mathrm{m}^{2}$ ). Normalization could be carried out by dividing both parameters by the BET surface area of each sample (Hsi et al. 2002). Thus, it would be possible to investigate the simultaneous effect of sulfur content and $S_{\mathrm{BET}}$ on the mercury adsorption capacity of SACs. From the figure, AC-DMDS possessed about $0.56 \mathrm{mg}$ sulfur per unit of area $\left(\mathrm{m}^{2}\right)$; however, the value in the case of $\mathrm{AC}-\mathrm{S}$ and $\mathrm{AC}-\mathrm{SO}_{2}$ was only about 0.2 . It might be one of the reasons of the higher mercury adsorption capacity of AC-DMDS. SEM-
Table 2 Rate constants of the pseudo-second-order model for mercury adsorption from aqueous phase by the sulfurized and sulfur-free ACs at different temperatures

Table 3 Parameters of Freundlich and Langmuir isotherm models for mercury adsorption from aqueous phase by the sulfurized and sulfur-free ACs at different temperatures

\begin{tabular}{|c|c|c|c|c|c|c|}
\hline \multicolumn{2}{|c|}{ Samples/temperature $\left({ }^{\circ} \mathrm{C}\right)$} & \multicolumn{5}{|c|}{ Pseudo-second-order kinetic model $q_{\mathrm{t}}=q_{\mathrm{e}} \frac{q_{\mathrm{e}} k_{2} t}{1+q_{\mathrm{e}} k_{2} t}$} \\
\hline & & $\overline{k_{2}}$ & $q_{\mathrm{e}, \text { calc. }}$ & $h_{\mathrm{i}}$ & $R^{2}$ & RMSE \\
\hline \multirow[t]{3}{*}{$\mathrm{AC}$} & 30 & $3.5 \times 10^{-4}$ & 99.40 & 3.46 & 0.99 & 2.67 \\
\hline & 45 & $3.6 \times 10^{-4}$ & 108.31 & 4.22 & 0.97 & 5.34 \\
\hline & 60 & $5.5 \times 10^{-4}$ & 118.27 & 7.69 & 0.94 & 7.39 \\
\hline \multirow[t]{3}{*}{ AC-DMDS } & 30 & $2.5 \times 10^{-5}$ & 195.64 & 0.96 & 0.99 & 3.42 \\
\hline & 45 & $7.6 \times 10^{-5}$ & 197.59 & 2.97 & 0.98 & 8.15 \\
\hline & 60 & $8.1 \times 10^{-5}$ & 218.20 & 3.86 & 0.99 & 6.93 \\
\hline \multirow[t]{3}{*}{$\mathrm{AC}-\mathrm{S}$} & 30 & $1.7 \times 10^{-4}$ & 140.80 & 3.37 & 0.99 & - \\
\hline & 45 & - & - & - & - & - \\
\hline & 60 & - & - & - & - & - \\
\hline \multirow[t]{3}{*}{$\mathrm{AC}-\mathrm{SO}_{2}$} & 30 & $8.0 \times 10^{-5}$ & 149.33 & 1.78 & 0.99 & 4.26 \\
\hline & 45 & $1.1 \times 10^{-4}$ & 155.63 & 2.66 & 0.97 & 7.11 \\
\hline & 60 & $1.5 \times 10^{-4}$ & 174.25 & 4.55 & 0.89 & 13.93 \\
\hline
\end{tabular}

\begin{tabular}{|c|c|c|c|c|c|c|c|c|c|}
\hline \multicolumn{2}{|c|}{ Samples/temperature $\left({ }^{\circ} \mathrm{C}\right)$} & \multicolumn{4}{|c|}{ Langmuir model $q_{\mathrm{e}}=\frac{q_{\mathrm{m}} K_{\mathrm{L}} C_{\mathrm{e}}}{1+K_{\mathrm{L}} C_{\mathrm{e}}}$} & \multicolumn{4}{|c|}{ Freundlich model $q_{\mathrm{e}}=K_{\mathrm{F}} C_{\mathrm{e}}^{1 / n}$} \\
\hline & & $q_{\mathrm{m}}$ & $K_{\mathrm{L}}$ & $\mathrm{R}^{2}$ & RMSE & $K_{\mathrm{F}}$ & $1 / n$ & $R^{2}$ & RMSE \\
\hline \multirow[t]{3}{*}{$\mathrm{AC}$} & 30 & 455 & 0.005 & 0.90 & 29.12 & 8.8 & 0.60 & 0.90 & 36.95 \\
\hline & 45 & 472 & 0.009 & 0.98 & 15.54 & 15.9 & 0.56 & 0.94 & 24.10 \\
\hline & 60 & 578 & 0.008 & 0.89 & 36.83 & 15.0 & 0.60 & 0.89 & 44.65 \\
\hline \multirow[t]{3}{*}{ AC-DMDS } & 30 & 441 & 0.217 & 0.96 & 29.47 & 155.8 & 0.21 & 0.90 & 52.37 \\
\hline & 45 & 444 & 0.289 & 0.90 & 39.57 & 186.7 & 0.17 & 0.96 & 24.09 \\
\hline & 60 & 474 & 0.484 & 0.88 & 69.83 & 213.1 & 0.18 & 0.96 & 26.24 \\
\hline \multirow[t]{3}{*}{$\mathrm{AC}-\mathrm{S}$} & 30 & 529 & 0.020 & 0.94 & 35.15 & 58.9 & 0.37 & 0.92 & 42.27 \\
\hline & 45 & 563 & 0.023 & 0.92 & 45.00 & 67.0 & 0.37 & 0.99 & 16.95 \\
\hline & 60 & 531 & 0.045 & 0.96 & 34.80 & 93.7 & 0.31 & 0.97 & 28.93 \\
\hline \multirow[t]{3}{*}{$\mathrm{AC}-\mathrm{SO}_{2}$} & 30 & 523 & 0.022 & 0.96 & 24.62 & 71.2 & 0.33 & 0.99 & 12.65 \\
\hline & 45 & 496 & 0.074 & 0.92 & 35.52 & 129.2 & 0.25 & 0.98 & 19.08 \\
\hline & 60 & 510 & 0.086 & 0.95 & 25.96 & 148.2 & 0.23 & 0.96 & 26.83 \\
\hline
\end{tabular}




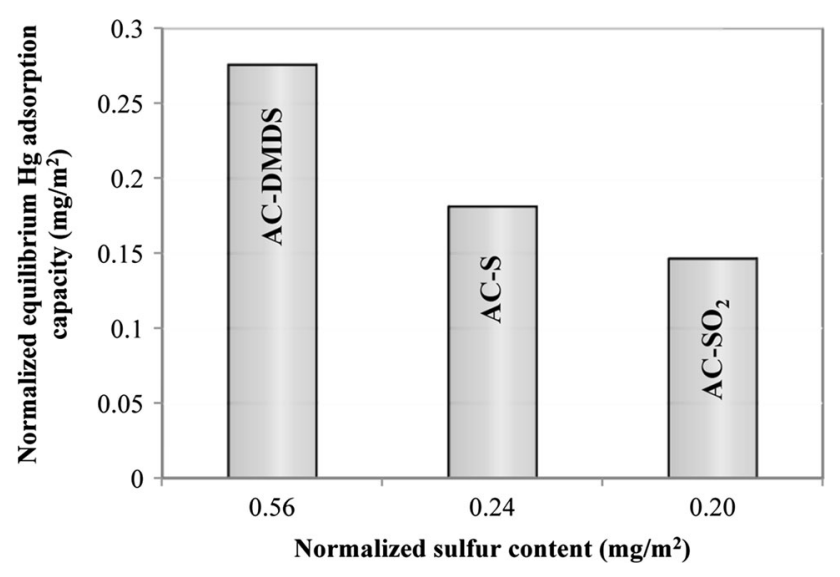

Fig. 1 Relation between the normalized bulk sulfur content and the normalized equilibrium mercury adsorption capacity of SACs

EDAX analysis on the sulfurized samples after mercury adsorption (Fig. 2) confirms that there is a direct correlation between the amount of sulfur on the surface of SACs and the amount of mercury adsorbed. Mercury accumulation on the surface of SACs increases at the points with larger sulfur concentrations.

The different types of sulfur-containing groups introduced into the samples' structure also have a role in their different mercury adsorption capacities. The results of FTIR tests have shown that the main sulfur functionalities of AC-S were the organic (thiophenic) and oxidized forms (Asasian and Kaghazchi 2013b). Similar results were observed in the case of $\mathrm{AC}-\mathrm{SO}_{2}$ (Asasian et al. 2014). However, in the structure of AC-DMDS, the organic forms of sulfur including sulfide and disulfide were detected (Asasian and Kaghazchi 2012). Furthermore, in order to evaluate the presence of unreacted elemental sulfur in the adsorbents' structures, the authors followed the procedure suggested by Danwanichakul (Danwanichakul et al. 2008; Asasian and Kaghazchi 2012). The results indicated no elemental sulfur in the structure of $\mathrm{AC}-\mathrm{S}$ and $\mathrm{AC}-\mathrm{SO}_{2}$ (the samples sulfurized at high temperatures). On the other hand, one-fourth $(25 \mathrm{wt} \%)$ of the bulk sulfur content of AC-DMDS was unreacted and elemental (Asasian and Kaghazchi 2012). The reader is referred to the previously published works of this group (Asasian and Kaghazchi 2012, 2013b; Asasian et al. 2014) for the detailed information about the FTIR spectra of the sulfurized samples, analysis of peaks, and the exact procedure of the test applied for the determination of unreacted sulfur. The manuscript would be prolonged too much, by repeating of the explanations. The higher mercury adsorption capacity of AC-DMDS than $\mathrm{AC}-\mathrm{SO}_{2}$ and $\mathrm{AC}-\mathrm{S}$ may be the consequence of the higher affinity of unreacted sulfur, sulfide, and disulfide groups toward mercury ions compared to the thiophenic and/or oxidized forms.
The organic sulfur functionalities (mainly thiophenes) and the oxidized sulfur forms in spite of having lower attraction toward mercury ions were more stable than the others, because of being exposed to a high-temperature treating stage. The presence of unstable sulfur groups on the surface of SACs may result in sulfur leaching during the wastewater treatment process. It was investigated in the present work by evaluating the treated solutions (after contact with SACs) for the presence of sulfur compounds including sulfide $\left(\mathrm{S}^{2-}\right)$, sulfite $\left(\mathrm{SO}_{3}^{2-}\right)$, and sulfate $\left(\mathrm{SO}_{4}^{2-}\right)$ according to the standard methods (Eaton et al. 2005). The concentration of these ions in the aqueous solutions treated with $\mathrm{AC}-\mathrm{S}$ and $\mathrm{AC}-\mathrm{SO}_{2}$ was negligible. In contrast, the following concentrations were detected in the aqueous solution after treating with AC-DMDS: $\mathrm{S}^{2-}=2, \mathrm{SO}_{3}^{-}=$ 6 and $\mathrm{SO}_{4}^{2-}<1 \mathrm{mg} / \mathrm{L}$ (Asasian and Kaghazchi 2012). The leaching of sulfur compounds into wastewater after contact with AC-DMDS leads wastewater to be polluted, and so it is considered as one of the disadvantages of using this sorbent.

The involvement of sulfur functionalities in the adsorption of mercury by the sulfurized activated carbons was further verified by comparison of the XPS spectra of AC-DMDS before and after applying for mercury adsorption (Fig. 3). Figure 3a, b shows the XPS spectra of the mercury-saturated AC and mercury-saturated AC-DMDS in $\mathrm{Hg}_{4 \mathrm{f}}$ region, respectively. Generally, the detection and speciation of the types of mercury compounds via XPS spectra $\left(\mathrm{Hg}_{4 \mathrm{f}}\right)$ is not very simple. However, some differences in the location and size of the peaks in Fig. $3 a, b$ could be observed. The binding energy of $\sim 101 \mathrm{eV}$ for $4 \mathrm{f}_{7 / 2}$ in the spectra of $\mathrm{Hg}$-saturated AC (Fig. 3a) confirmed the presence of $\mathrm{Hg}-\mathrm{O}$ and $\mathrm{Hg}-\mathrm{Cl}$ bonds (Nelson et al. 2000; Wilcox et al. 2011). In the case of mercury-saturated AC-DMDS (Fig. 3b), the corresponding peak shifted to $\sim 99.9 \mathrm{eV}$. It indicated the presence of $\mathrm{Hg}-\mathrm{S}$ addition to $\mathrm{Hg}-\mathrm{Cl}$ and $\mathrm{Hg}-\mathrm{O}$. Similar binding energy for $\mathrm{Hg}-\mathrm{S}$ is proposed in several studies (Nelson et al. 2000; Pouli et al. 2001; Wang et al. 2001). In Fig. 3c, d, the XPS spectra ( $S_{2 p}$ region) of AC-DMDS before and after adsorption of mercury are shown. Considering the binding energies of elemental sulfur $(164.05 \mathrm{eV})$ and organic sulfur (163-164.1 eV) (Humeres et al. 2003; Feng et al. 2006b), the existence of both forms on the surface of AC-DMDS is possible (Fig. 3c). The peaks appeared in Fig. 3d (ACDMDS after mercury adsorption) are different from Fig. 3c. The authors believed that this may be a sign of the involvement of sulfur-containing groups in adsorption of mercury ions via chemical reaction.

The kinetic and equilibrium constants obtained at different temperatures (Tables 2 and 3) could be applied for the calculation of additional useful parameters. For 

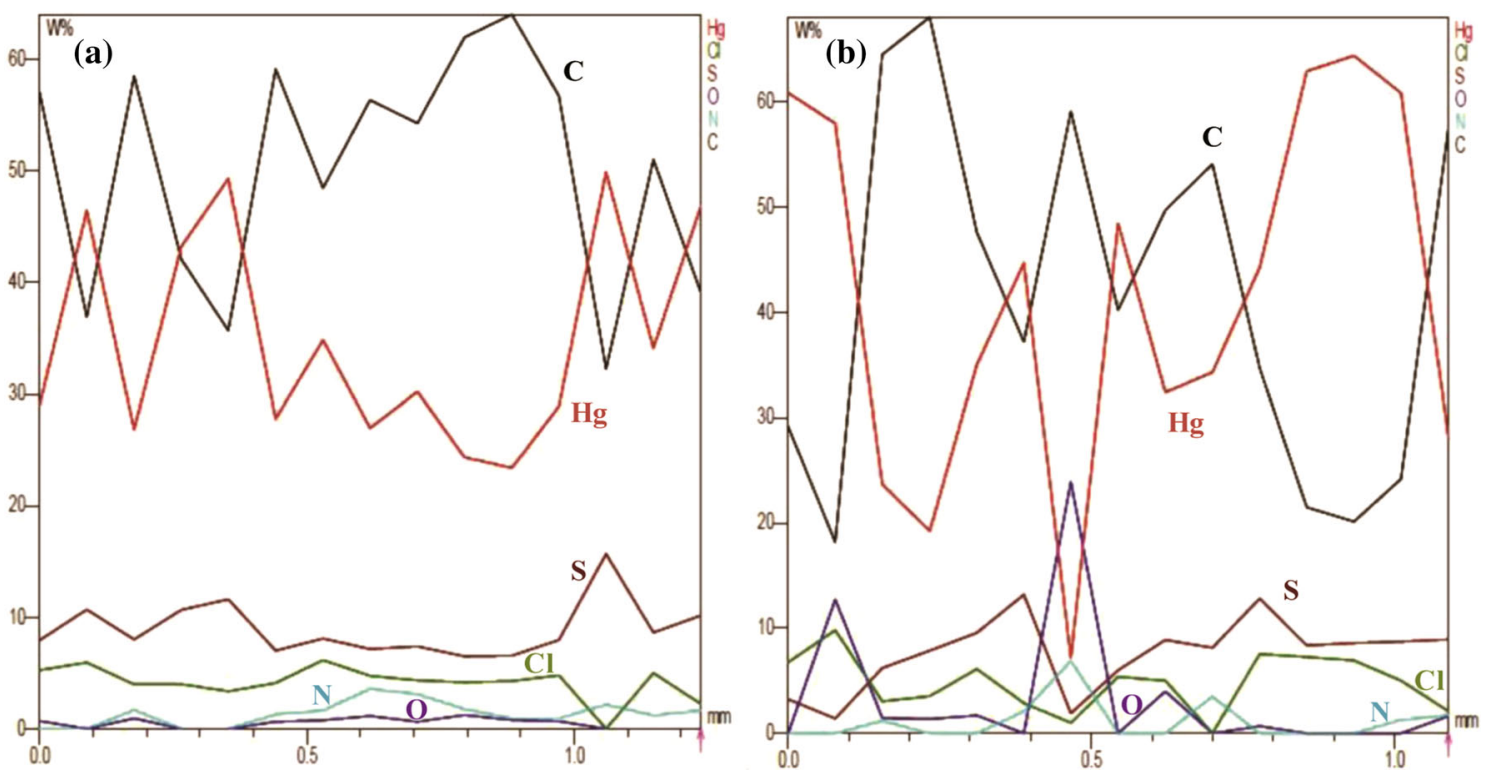

Fig. 2 Surface concentrations of Hg-saturated SACs measured by EDAX, line scan analysis a AC-DMDS and b AC-S

(a)

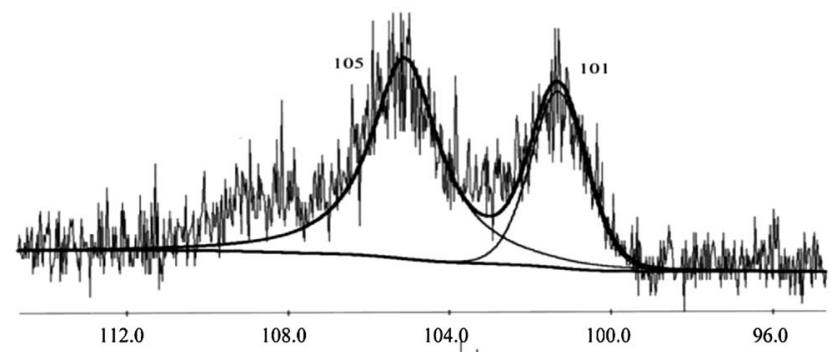

(b)

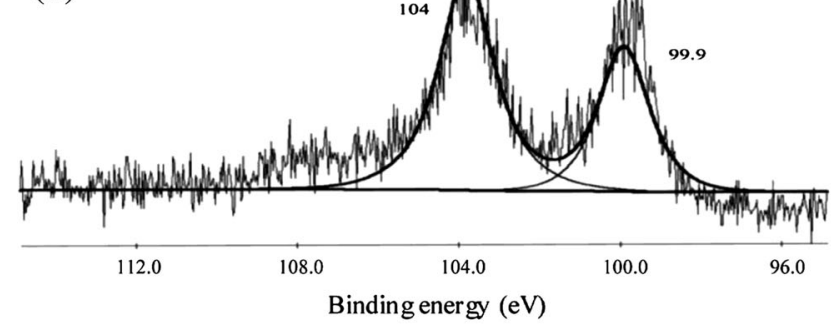

(c)

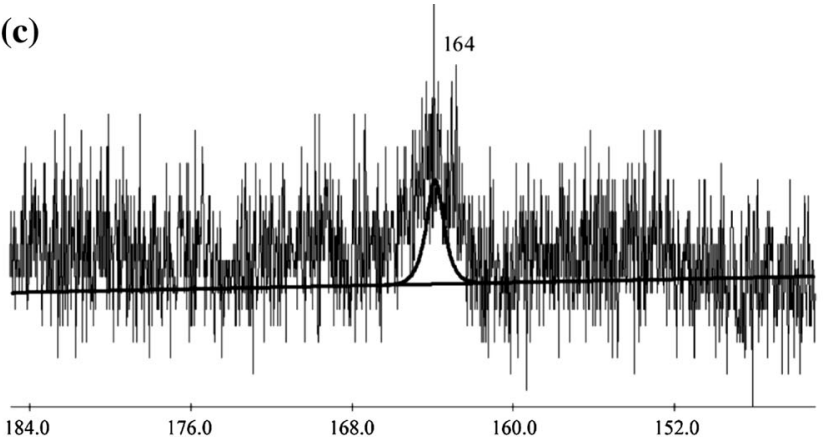

(d)

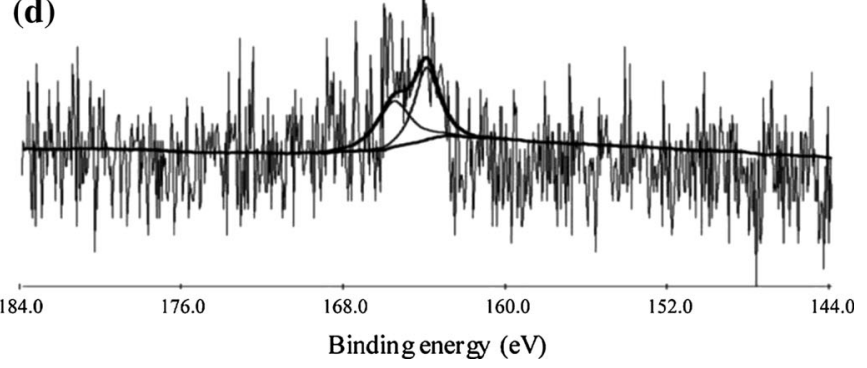

Fig. 3 XPS spectra of a Hg-saturated AC and b Hg-saturated AC-DMDS in $\mathrm{Hg}_{4 \mathrm{f}}$ region and for $\mathbf{c}$ AC-DMDS and d Hg-saturated AC-DMDS in $\mathrm{S}_{2 \mathrm{p}}$ region

example, the activation parameters of mercury adsorption were calculated using the kinetic data, Arrhenius, and Eyring equations (Saha and Chowdhury 2011; Inglezakis and Zorpas 2012) (Table 4). Mercury adsorption onto the SACs was associated with the higher activation energies rather than AC; however, none of the values reached to the formation heat of $\mathrm{Hg}-\mathrm{S}$. This is because the activation energy in the adsorption processes not only represents the heat of chemical reaction between $\mathrm{S}$ and $\mathrm{Hg}$ but also includes the necessary energy for other complex mechanisms involved. Some of the possible mechanisms are as follows: metal ion dehydration, film diffusion, intraparticle diffusion, desorption of $\mathrm{H}_{2} \mathrm{O}$ molecules, and complexation (Krishnan and Anirudhan 2002b; Erenturk and Malkoc 2007). Facilitating of mercury-sulfur interactions when sulfur particles are accompanying by a porous sorbent is a consequence of the relatively lower activation energy. It is notable that such an interaction cannot occur easily at room 
Table 4 Activation and thermodynamic parameters of mercury adsorption by the sulfurized and sulfur-free ACs

\begin{tabular}{|c|c|c|c|c|c|c|c|}
\hline \multirow[t]{2}{*}{ Adsorbent } & \multicolumn{4}{|c|}{ Activation parameters $^{\mathrm{a}}$} & \multicolumn{3}{|c|}{ Thermodynamic parameters ${ }^{\mathrm{b}}$} \\
\hline & $\begin{array}{l}E_{\mathrm{a}} \\
(\mathrm{KJ} / \mathrm{mol})\end{array}$ & $\Delta H^{\neq}(\mathrm{KJ} / \mathrm{mol})$ & $\Delta S^{\neq}(\mathrm{J} / \mathrm{mol} \mathrm{K})$ & $\Delta G^{\neq}(\mathrm{KJ} / \mathrm{mol}) @ 30{ }^{\circ} \mathrm{C}$ & $\begin{array}{l}\Delta H^{0} \\
(\mathrm{KJ} / \mathrm{mol})\end{array}$ & $\begin{array}{l}\Delta S^{0} \\
(\mathrm{~J} / \mathrm{mol} \mathrm{K})\end{array}$ & $\Delta \mathrm{G}^{0}(\mathrm{KJ} / \mathrm{mol}) @ 30^{\circ} \mathrm{C}$ \\
\hline $\mathrm{AC}$ & 12.31 & 9.68 & -279.71 & 94.43 & 19.78 & 72.48 & -2.18 \\
\hline AC-DMDS & 33.05 & 30.41 & -231.44 & 100.54 & 24.40 & 118.00 & -11.36 \\
\hline $\mathrm{AC}-\mathrm{S}$ & - & - & - & - & 21.95 & 91.53 & -5.78 \\
\hline $\mathrm{AC}-\mathrm{SO}_{2}$ & 18.21 & 15.57 & -272.06 & 98.01 & 38.21 & 147.51 & -6.48 \\
\hline
\end{tabular}

${ }^{\mathrm{a}}$ Calculated from the kinetic data, Arrhenius $\left(\ln K_{2}=\ln A-E_{a} / \mathrm{RT}\right)$, and Eyring $\left(\ln \left(K_{2} / T\right)=\left[\ln \left(k_{\mathrm{b}} / h\right)+\left(\Delta S^{\neq} / R\right)\right]-\Delta H^{\neq} / \mathrm{RT}\right)$ equations

b Calculated from the isotherm data and Van't Hoff equation $\left(\Delta G^{0}=\Delta H^{0}-T \Delta S^{0}=-\mathrm{RT} \ln K_{\mathrm{D}}\right)$

temperature, when both sulfur and mercury are available alone (Marsh and Rodriguez-Reinoso 2006).

The values obtained for the thermodynamic parameters from the isotherm data and the Van't Hoff equation (Aksu and İşoğlu 2005; Saha and Chowdhury 2011) (Table 4) indicated the spontaneity of the adsorption processes $\left(\Delta G^{0}<0\right)$. The standard activation entropy $\left(\Delta S^{\neq}\right)$and the standard entropy of adsorption change $\left(\Delta S^{0}\right)$ indicated two different meanings; the negative values of the first parameter suggested an associative adsorption mechanism. The second parameter with the positive value showed an increased randomness at the solid-solution interface during the sorption (Saha and Chowdhury 2011). The positive values of the standard activation enthalpy and enthalpy of adsorption change showed that the resultant of the involved mechanisms had a chemical nature.

\section{Mercury desorption by sulfurized activated carbons}

The efficiency of five different extractants for desorption of mercury from the saturated SACs and AC was compared. The solvents were chosen based on previous studies (Kadirvelu et al. 2004; Al Rmalli et al. 2008; Dias Filho et al. 2008). The experiments were carried out at different concentrations of extractants $(0.2-2 \mathrm{M})$, but for brevity, only the results of the highest concentration are presented in Table 5. None of the extractants were able to desorb mercury completely from the surfaces of the saturated sorbents. It verified the strength of the bonds formed between mercury and the active sites. Between the two acidic solutions, the ability of $\mathrm{HNO}_{3}$ was higher than $\mathrm{HCl}$. The weaker desorption capability of $\mathrm{HCl}$ under the conditions applied (concentration of $2 \mathrm{M}$ and shaking time of $24 \mathrm{~h}$ ) could be explained as follows: soaking $\mathrm{Hg}$-saturated sorbents in $\mathrm{HCl}$ for relatively long time and inserting $\mathrm{Cl}^{-}$ions to the sorbents' surfaces. The affinity of chloride ions to readsorb the released $\mathrm{Hg}$ ions (Inbaraj et al. 2009) weakened the performance of $\mathrm{HCl}$ for desorption to some extent (Inbaraj et al. 2009; Asasian et al. 2014).
Potassium halides desorb mercury by the exchange of $\mathrm{K}^{+}$ions with mercury cations. Among them, KI showed the most efficient performance. It was related to the higher solubility of iodide complexes compared to the bromide and chloride ones (Namasivayam and Periasamy 1993).

Another conclusion was the better performance of potassium halides in desorption of mercury from the surface of AC rather than the sulfurized ones. The opposite behavior was observed in the case of acidic extractants. It was caused by the different mechanisms directing desorption processes by the two kinds of extractants. As it was noted previously, potassium halides should exchange their $\mathrm{K}^{+}$ions with $\mathrm{Hg}$ cations previously adsorbed on the surfaces of AC and SACs, respectively, by oxygenated and sulfur-containing groups. Based on the HSAB theory, potassium and mercury ions belong to the hard and soft acids groups. In contrast, the oxygen- and sulfur-containing sites on the surfaces of AC and SACs are classified as hard and soft bases, respectively. So it is expected that the interation between $\mathrm{K}^{+}$ions (hard acid) and oxygen groups (hard base) occurs easier than that between $\mathrm{K}^{+}$ions and sulfur-containing groups.

In the case of acidic extractants, the determining mechanism was $\mathrm{pH}$ decreasing and the formation of large amounts of $\mathrm{H}^{+}$ions in solution as annoying species for mercury adsorption. Therefore, whatever the mercury adsorption capacity of an adsorbent was enhanced by $\mathrm{pH}$ increasing, the efficiency of acidic solutions for desorption of mercury from its surface was higher. Figure 4 shows that the adsorption capacities of SACs changed more significantly between the acidic and neutral $\mathrm{pH}$. Therefore, the acidification of solution is more beneficial for mercury desorption from the SACs compared to AC.

Finally, the performance of AC and SACs for use in four consecutive adsorption-desorption cycles was compared. The adsorption experiments of the cycles were performed under the following conditions: adsorbent weight: $0.1 \mathrm{~g}$, 
Table 5 Comparison of mercury desorption from the saturated sulfurized and sulfurfree ACs by different extractants

\begin{tabular}{lllll}
\hline Extractant (2M) & Adsorbent & Desorption percentage (\%) & Adsorbent & Desorption percentage (\%) \\
\hline $\mathrm{HCl}$ & AC & 26.18 & AC-S & 41.28 \\
$\mathrm{HNO}_{3}$ & & 53.82 & & 55.87 \\
$\mathrm{KCl}$ & 55.70 & & 48.67 \\
$\mathrm{KBr}$ & 64.17 & & 52.29 \\
$\mathrm{KI}$ & 81.01 & $\mathrm{AC}^{-\mathrm{SO}_{2}}$ & 56.05 \\
$\mathrm{HCl}$ & & & 49.41 \\
$\mathrm{HNO}{ }_{3}$ & AC-DMDS & 35.86 & & 56.06 \\
$\mathrm{KCl}$ & 54.70 & & 54.91 \\
$\mathrm{KBr}$ & 37.03 & 60.20 \\
$\mathrm{KI}$ & 50.25 & 63.88 \\
\hline
\end{tabular}

Fig. 4 Effect of initial pH of solution on the adsorption capacity of AC (straight line with circle), AC-DMDS (straight line with square), $\mathrm{AC}-$ $\mathrm{S}$ (straight line with triangle), and $\mathrm{AC}-\mathrm{SO}_{2}$ (straight line with asterisk). Distribution diagram of mercury species established with visual MINTEQ software for an initial concentration of $\mathrm{Hg}(\mathrm{II})=200 \mathrm{mg} / \mathrm{l}$ is also shown in the background, only major species are shown

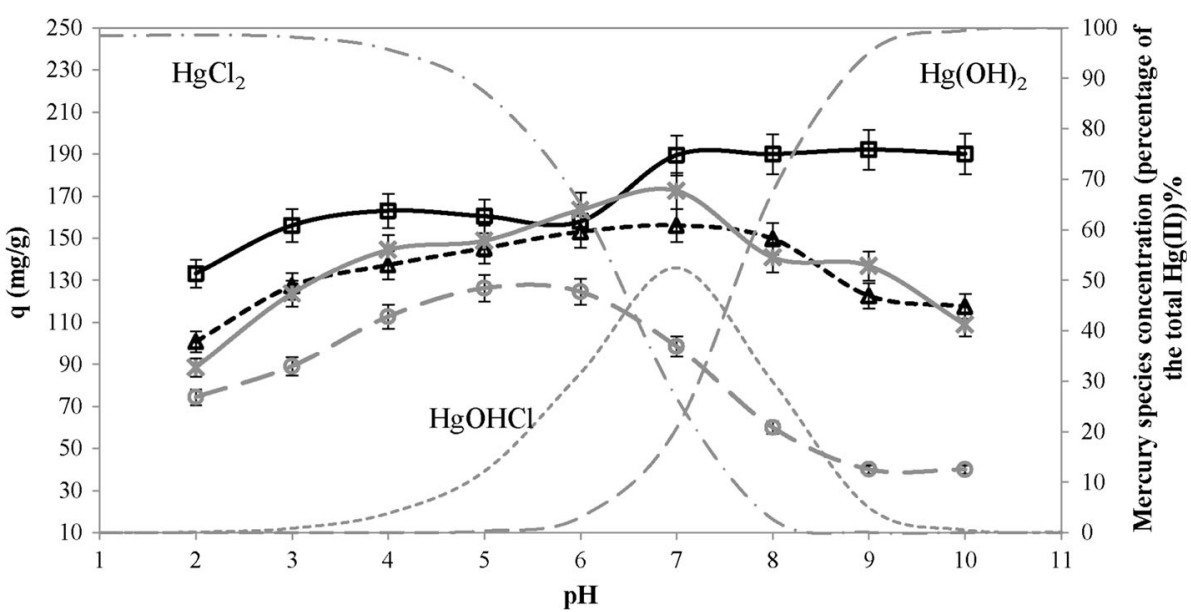

mercury solution volume: $100 \mathrm{~cm}^{3}$, initial $\mathrm{pH}$ of solution: 7.0, and initial mercury concentration: $100 \mathrm{mg} / \mathrm{L}$. The desorption conditions were as follows: adsorbent weight: $0.1 \mathrm{~g}$, extractant $\left(\mathrm{HNO}_{3}\right)$ solution volume: $50 \mathrm{~cm}^{3}$, and extractant solution concentration: 2 N. For both adsorption and desorption tests, the temperature, shaking speed, and contact time were chosen as $30{ }^{\circ} \mathrm{C}, 200 \mathrm{rpm}$, and $4 \mathrm{~h}$, respectively. It was observed that the adsorption capacity loss from the first to the forth cycle was only about $11.02 \mathrm{mg} / \mathrm{g}$ for AC sample. However, this value in the case of $\mathrm{AC}-\mathrm{DMDS}$ and $\mathrm{AC}-\mathrm{SO}_{2}$ increased to 33.59 and $83.82 \mathrm{mg} / \mathrm{g}$, respectively. The lower adsorption capacity loss of AC after the first cycle was related to the ability of $\mathrm{HNO}_{3}$ for elution of its micropores which are the main responsible sites for mercury sorption. On the other hand, in the case of the sulfurized samples, the key role of the sulfur functionalities in mercury adsorption was established. The results indicated that the use of acidic and/or potassium halide solutions alone was not enough for the recovery of inactive sulfur sites. Therefore, adding a reactivation step prior to each adsorption cycle was suggested to insert new sulfur-containing groups or activate the old functionalities.

\section{Conclusion}

The sulfurized ACs in spite of having lower surface areas and micropore volumes than the sulfur-free AC showed higher equilibrium mercury adsorption capacities. The SAC with the highest normalized sulfur content (mg S/ $\mathrm{m}^{2}$ ) showed the highest mercury adsorption capacity. The involvement of sulfur functionalities especially the elemental and organic sulfur in mercury adsorption was confirmed by investigating their surface chemical structure. The general disadvantage of SACs in the batch systems was their slower adsorption rates at the initial stages of contact; however, it could be compensated to some extent using the smaller particle sizes of the adsorbents or increasing temperature. The other limitation was the frustrating performance of the SACs in successive adsorption-desorption processes. It was found that the use of mercury extractants alone was not adequate for recovery of SACs. Among the three sulfurization methods, DMDS impregnation at room temperature was the simplest and the most efficient procedure in increasing the equilibrium adsorption capacity. However, heat treating of 
the sulfur-impregnated ACs at high-temperature furnaces has several advantages. For example, opening the occupied pores and increasing the porosity, stabilization of sulfur-containing groups, and minimization of sulfur leaching from the surface of SACs during the water treatment are of the advantages.

Acknowledgments The authors gratefully acknowledge the valuable support of the Separation Laboratory team. The assistances of Dr. M. Soleimani and the staff of the Instrumental Analysis Laboratory in the Chemical Engineering Department of Amirkabir University of Technology are also appreciated especially for providing the appropriate conditions to perform the atomic absorption tests.

\section{Abbreviations}

A

$C_{\mathrm{e}}$

$E_{\mathrm{a}}$

$h$

$h_{\mathrm{i}}$

$k_{2}$

$K_{\mathrm{D}}$

$K_{\mathrm{F}}$

$K_{\mathrm{L}}$

MIC \%

$n$

$q_{\mathrm{t}}$

$q_{\mathrm{e}}$

$q_{\mathrm{m}}$

$R$

$R^{2}$

RMSE

$S_{\text {BET }}$

$T$

$V_{\text {MIC }}$

$V_{\text {TOT }}$

$\Delta G^{0}$

$\Delta G^{\neq}$

$\Delta H^{0}$
Frequency factor in Arrhenius equation (g/mg min)

Solute concentration at equilibrium (mg/L)

Activation energy $(\mathrm{KJ} / \mathrm{mol})$

Initial adsorption rate $\left(=k_{2} q_{\mathrm{e}}^{2} ; \mathrm{mg} / \mathrm{g}\right.$ min $)$

Pseudo-second-order adsorption rate constant (g/mg min)

Dimensionless equilibrium constant

$\left(K_{\mathrm{L}} \times q_{\mathrm{m}}\right)$

Freundlich empirical constant (mg/g)

$(\mathrm{L} / \mathrm{mg})^{1 / \mathrm{n}}$

Langmuir empirical constant (L/mg)

$\left(V_{\text {MIC }} / V_{\text {TOT }}\right) \times 100(\%)$

Exponent in Freundlich isotherm

Amount of solute adsorbed at time $t(\mathrm{mg} / \mathrm{g})$

Amount of solute adsorbed at equilibrium (mg/g)

Monolayer adsorption capacity (mg/g)

Universal gas constant $(8.314 \mathrm{~J} / \mathrm{mol} \mathrm{K})$

Correlation coefficient

Root-mean-squared error

BET-specific surface area $\left(\mathrm{m}^{2} / \mathrm{g}\right)$

Absolute temperature $(\mathrm{K})$

Micropore volume (HK method) $\left(\mathrm{cm}^{3} / \mathrm{g}\right)$

Total pore volume $\left(\mathrm{cm}^{3} / \mathrm{g}\right)$

Standard Gibbs free energy of adsorption change $\left(=\Delta H^{0}-T \Delta S^{0} ; \mathrm{KJ} / \mathrm{mol}\right)$

Standard activation free $\operatorname{energy}\left(=\Delta H^{\neq}-T \Delta S^{\neq} ; \mathrm{KJ} / \mathrm{mol}\right)$

Standard enthalpy of adsorption change $(\mathrm{KJ} / \mathrm{mol})$
Plank's constant $\left(=6.6261 \mathrm{e}^{-34} \mathrm{~J}\right.$ s $)$
$\Delta H^{\neq} \quad$ Standard activation enthalpy $(\mathrm{KJ} / \mathrm{mol})$

$\Delta S^{0} \quad$ Standard entropy of adsorption change $(\mathrm{J} / \mathrm{mol} \mathrm{K})$

$\Delta S^{\neq} \quad$ Standard activation entropy $(\mathrm{J} / \mathrm{mol} \mathrm{K})$

\section{References}

Aksu Z, İşoğlu İA (2005) Removal of copper (II) ions from aqueous solution by biosorption onto agricultural waste sugar beet pulp. Process Biochem 40:3031-3044

Al Rmalli SW, Dahmani AA, Abuein MM, Gleza AA (2008) Biosorption of mercury from aqueous solutions by powdered leaves of castor tree (Ricinus communis L.). J Hazard Mater 152:955-959

Asasian N, Kaghazchi T (2012) Comparison of dimethyl-disulfide and carbon-disulfide in sulfurization of activated carbons for producing mercury adsorbents. Ind Eng Chem Res 51:12046-12057

Asasian N, Kaghazchi T (2013a) A comparison on efficiency of virgin and sulfurized agro-based adsorbents for mercury removal from aqueous systems. Adsorption 19:189-200

Asasian N, Kaghazchi T (2013b) Optimization of activated carbon sulfurization to reach adsorbent with the highest capacity for mercury adsorption. Separ Sci Technol 48:1-14

Asasian N, Kaghazchi T, Faramarzi A, Hakimi-Siboni A, AsadiKesheh R, Kavand M, Mohtashami S-A (2014) Enhanced mercury adsorption capacity by sulfurization of activated carbon with $\mathrm{SO}_{2}$ in a bubbling fluidized bed reactor. J Taiwan Inst Chem E 45:1588-1596

Danwanichakul P, Dechojarasrri D, Meesumrit S, Swangwareesakul S (2008) Influence of sulfur-crosslinking in vulcanized rubber chips on mercury(II) removal from contaminated water. J Hazard Mater 154:1-8

Dias Filho NL, Okajima GL, Pires G, Costa RM, do Carmo DR, Rosa AH (2008) Voltammetry of mercury (II) based on an organo-clay modified graphite electrode. Port Electrochim Acta 26:163-179

Eaton AD, Clesceri LS, Rice EW, Greenberg AE, Franson MAH (2005) Standard methods for the examination of water and wastewater. American Public Health Association, Washington

Edwin VA (2008) Surface modification of activated carbon for enhancement of Nickel(II) adsorption. E-J Chem 5:814-819

Eisler R (2006) Mercury hazards to living organisms. CRC Press, Taylor \& Francis Group, Boca Raton

Erenturk S, Malkoc E (2007) Removal of lead(II) by adsorption onto Viscum album L.: effect of temperature and equilibrium isotherm analyses. Appl Surf Sci 253:4727-4733

Feng W, Borguet E, Vidic RD (2006a) Sulfurization of a carbon surface for vapor phase mercury removal-II: sulfur forms and mercury uptake. Carbon 44:2998-3004

Feng W, Kwon S, Feng X, Borguet E, Vidic RD (2006b) Sulfur impregnation on activated carbon fibers through $\mathrm{H}_{2} \mathrm{~S}$ oxidation for vapor phase mercury removal. J Environ Eng 132:292-300

Freundlich HMF (1906) Over the adsorption in solution. J Phys Chem $57: 385-470$ 
Ho YS, McKay GM (1999) Pseudo-second order model for sorption processes. Process Biochem 34:451-465

Hsi H-C, Rood MJ, Rostam-Abadi M, Chen S, Chang R (2001) Effects of sulfur impregnation temperature on the properties and mercury adsorption capacities of activated carbon fibers (ACFs). Environ Sci Technol 35:2785-2791

Hsi HC, Rood MJ, ASCE M, Rostam-Abadi M, Chen S, Chang R (2002) Mercury adsorption properties of sulfur-impregnated adsorbents. J Environ Eng 128:1080-1089

Huber K (1997) Mercury use: wastewater treatment plants. Draft Wisconsin mercury sourcebook. http://infohouse.p2ric.org/ref/ 04/03851/waste.pdf. Accessed Feb 2015

Humeres E, Peruch MGB, Moreira RFPM, Schreiner W (2003) Reactive intermediates of the reduction of $\mathrm{SO}_{2}$ on activated carbon. J Phys Org Chem 16:824-830

Inbaraj BS, Wang JS, Lu JF, Siao FY, Chen BH (2009) Adsorption of toxic mercury(II) by an extracellular biopolymer poly( $\gamma$-glutamic acid). Bioresour Technol 100:200-207

Inglezakis VJ, Zorpas AA (2012) Heat of adsorption, adsorption energy and activation energy in adsorption and ion exchange systems. Desalin Water Treat 39:149-157

Kadirvelu K, Kavipriya M, Karthika C, Vennilamani N, Pattabhi S (2004) Mercury (II) adsorption by activated carbon made from sago waste. Carbon 42:745-752

Korpiel JA, Vidic RD (1997) Effect of sulfur impregnation method on activated carbon uptake of gas-phase mercury. Environ Sci Technol 31:2319-2325

Krishnan KA, Anirudhan TS (2002a) Removal of mercury (II) from aqueous solutions and chlor-alkali industry effluent by steam activated and sulphurised activated carbons prepared from bagasse pith: kinetics and equilibrium studies. J Hazard Mater 92:161-183

Krishnan KA, Anirudhan TS (2002b) Uptake of heavy metals in batch systems by sulfurized steam activated carbon prepared from sugarcane bagasse pith. Ind Eng Chem Res 41:5085-5093

Langmuir I (1918) The adsorption of gases on plane surface of glass, mica and platinum. J Am Chem Soc 40:1361-1403

Liu W, Vidic RD, Brown TD (1998) Optimization of sulfur impregnation protocol for fixed-bed application of activated carbon-based sorbents for gas-phase mercury removal. Environ Sci Technol 32:531-538

Liu W, Vidic RD, Brown TD (2000) Optimization of high temperature sulfur impregnation on activated carbon for permanent sequestration of elemental mercury vapors. Environ Sci Technol 34:483-488

Lowell S, Shields JE, Thomas MA, Thommes M (2004) Characterization of porous materials and powders: surface area, pore size and density. Springer, Dordrecht

Macias-Garcia A, Valenzuela-Calahorro C, Gomez-Serrano V, Espinosa-Mansilla A (1993) Adsorption of $\mathrm{Pb}^{2+}$ by heat-treated and sulfurized activated carbon. Carbon 31:1249-1255

Macias-Garcia A, Gomez-Serrano V, Alexandre-Franco MF, Valenzuela-Calahorro C (2003) Adsorption of cadmium by sulphur dioxide treated activated carbon. J Hazard Mater 103:141-152

Macias-Garcia A, Valenzuela-Calahorro C, Espinosa-Mansilla A, Bernalte-Garcia A, Gomez-Serrano V (2004) Adsorption of $\mathrm{Pb}^{2+}$ in aqueous solution by $\mathrm{SO}_{2}$-treated activated carbon. Carbon 42:1755-1764

Marsh H, Rodriguez-Reinoso F (2006) Activated carbon. Elsevier, Amsterdam

Mohan D, Gupta VK, Srivastava SK, Chander S (2001) Kinetics of mercury adsorption from wastewater using activated carbon derived from fertilizer waste. Colloid Surf A 177:169-181

Nabais JV, Carrott PJM, Ribeiro Carrott MML, Belchior M, Boavida D, Diall T, Gulyurtlu I (2006) Mercury removal from aqueous solution and flue gas by adsorption on activated carbon fibres. Appl Surf Sci 252:6046-6052

Nam KH, Gomez-Salazar S, Tavlarides LL (2003) Mercury (II) adsorption from wastewaters using a thiol functional adsorbent. Ind Eng Chem Res 42:1955-1964

Namasivayam C, Periasamy K (1993) Bicarbonate-treated peanut hull carbon for mercury (II) removal from aqueous solution. Water Res 27:1663-1668

Nelson AJ, Reynolds JG, Baumann TF, Fox GA (2000) X-ray photoemission investigation of binding sites in polymer-bound thiacrowns used for environmental remediation of $\mathrm{Hg}$ in aqueous solutions. Appl Surf Sci 167:205-215

Otani Y, Emi H, Kanaoka C, Uchijima I, Nishino H (1988) Removal of mercury vapor from air with sulfur-impregnated adsorbents. Environ Sci Technol 22:708-711

Pearson RG (1998) Absolute electro negativity and hardness: application to inorganic chemistry. Inorg Chem 27:734-740

Pouli P, Emmony DC, Madden CE, Sutherland I (2001) Analysis of the laser-induced reduction mechanisms of medieval pigments. Appl Surf Sci 173:252-261

Ranganathan K, Balasubramanian N (2002) Testing of sulphide loaded activated carbon for uptake of $\mathrm{Hg}$ (II) from aqueous solution. Eng Life Sci 2:127-129

Saha P, Chowdhury S (2011) Insight into adsorption thermodynamics. In: Tadashi M (ed) Thermodynamics, InTech. http://www. intechopen.com/books/thermodynamics/insight-into-adsorptionthermodynamics. Accessed Feb 2015

Silva HS, Ruiz SV, Granados DL, Santangelo JM (2010) Adsorption of mercury (II) from liquid solutions using modified activated carbons. Mater Res 13:129-134

Sinha RK, Walker PL Jr (1972) Removal of mercury by sulfurized carbons. Carbon 10:754-756

Skodras G, Orfanoudaki Th, Kakaras E, Sakellaropoulos GP (2002) Production of special activated carbon from lignite for environmental purposes. Fuel Process Technol 77-78:75-87

Skodras G, Ir Diamantopoulou, Sakellaropoulos GP (2007) Role of activated carbon structural properties and surface chemistry in mercury adsorption. Desalination 210:281-286

Smiciklas ID, Milonjic SK, Pfendt P, Raicevic S (2000) The point of zero charge and sorption of cadmium (II) and strontium (II) ions on synthetic hydroxyapatite. Sep Purif Technol 18:185-194

Tseng R-L, Wu F-C (2008) Inferring the favorable adsorption level and the concurrent multi-stage process with the Freundlich constant. J Hazard Mater 155:277-287

U.S. Environmental Protection Agency home page (1997) Mercury study report to congress, Volume III: fate and transport of mercury in the environment. Office of air quality planning and standards and office of research and development. EPA-452/R97-005. http://www.epa.gov/ttn/atw/112nmerc/volume3.pdf. Accessed Feb 2015

Vitolo S, Pini R (1999) Deposition of sulfur from $\mathrm{H}_{2} \mathrm{~S}$ on porous adsorbents and effect on their mercury adsorption capacity. Geothermic 28:341-354

Vitolo S, Seggiani M (2002) Mercury removal from geothermal exhaust gas by sulfur-impregnated and virgin activated carbons. Geothermics 31:431-442

Wajima T, Murakami K, Kato T, Sugawara K (2009) Heavy metal removal from aqueous solution using carbonaceous $\mathrm{K}_{2} \mathrm{~S}$-impregnated adsorbent. J Environ Sci China 21:1730-1734

Wang H, Zhang JR, Zhu JJ (2001) A microwave assisted heating method for the rapid synthesis of sphalrite-type mercury sulfide nanocrystals with different sizes. J Cryst Growth 233:829-836

Wilcox J, Sasmaz E, Kirchofer A, Lee SS (2011) Heterogeneous mercury reaction chemistry on activated carbon. J Air Waste Manag Assoc 61:418-426 
Yin CY, Aroua MK, Daud WMAW (2007) Review of modifications of activated carbon for enhancing contaminant uptakes from aqueous solutions. Sep Purif Technol 52:403-415
Zhang J, Bishop PL, Asce F (2003) Stabilization/solidification of high mercury wastes with reactivated carbon. Pract Period Hazard Toxic Radioact Waste Mgmt 7:31-36 